\section{Effects of self monitoring of triglyceride concentrations in non-insulin dependent diabetes}

\author{
M W Stewart, M F Laker, K G M M Alberti
}

Department of Medicine, Medical School, University of Newcastle upon Tyne, Newcastle upon Tyne NE2 4HH

M W Stewart, research registrar

K G M M Alberti, professor of medicine

\section{Department of Clinical}

Biochemistry and

Metabolic Medicine

M F Laker, reader in clinical

biochemistry

Correspondence to:

Dr Stewart.

BMf 1993;306:493 diabetes mellitus.
Cardiovascular disease is three times more common in diabetic patients than the non-diabetic population and is the main cause of death in people with non-insulin dependent diabetes mellitus. ${ }^{1}$ The importance of the plasma triglyceride concentration as a risk factor for coronary heart disease in the general population is still uncertain. In diabetic patients, however, triglyceride concentrations are an important predictor of coronary heart disease, ${ }^{2}$ and patients with non-insulin dependent diabetes are twice as likely as non-diabetic people to be dyslipidaemic, ${ }^{3}$ hypertriglyceridaemia being the commonest lipid abnormality. ${ }^{4}$ As diabetic patients have little feedback on their daily lipid concentrations we aimed at determining whether self monitoring of plasma triglyceride concentrations improved lipid concentrations (and perhaps indirectly glucose concentrations) in patients with non-insulin dependent

\section{Methods and results}

Twelve non-insulin dependent diabetic patients with fasting plasma triglyceride concentrations $>1.7$ $\mathrm{mmol} / \mathrm{l}$ were recruited from diabetic clinics in Newcastle upon Tyne. The local ethical committee's approval and patients' informed consent were obtained for the study. No patients had fasting triglyceride concentrations $>5.0 \mathrm{mmol} / \mathrm{h}$ or cholesterol concentrations $>7.8 \mathrm{mmol} / 1$, none were receiving lipid lowering treatment or insulin, and all had a haemoglobin $A_{1 c}$ concentration $<9.5$ (reference range $2 \cdot 8-4 \cdot 4$ ) $\%$ and a body mass index $<35 \mathrm{~kg} / \mathrm{m}^{2}$. At the time of recruitment the patients were reminded of the British Diabetic Association's dietary recommendations (55\% carbohydrate, $30 \%$ fat, and $15 \%$ protein). ${ }^{5}$ The patients were divided into two groups matched for age, sex, body mass index, and fasting plasma triglyceride concentrations. Patients in one group were given Reflotron machines (Boehringer Mannheim, Germany) and were asked to measure their triglyceride concentrations at home, before meals and before going to bed, twice a week and to record the results in diaries. The other group acted as controls. All patients attended the clinic monthly for six months. They fasted before each visit, when they were weighed and had blood samples taken for measurement of triglyceride, cholesterol, high density lipoprotein cholesterol, apolipoprotein B, and haemoglobin $\mathbf{A}_{1 \mathrm{c}}$ concentrations.
The mean plasma triglyceride concentration of the patients who monitored themselves fell significantly during the study $(2.7(\mathrm{SD} 0.7) \mathrm{mmol} / \mathrm{l}$ at the start $v 1.6$ (SD 0.4$) \mathrm{mmol} / \mathrm{l}$ at the end; difference $=1 \cdot 1 \quad(95 \%$ confidence interval $-0 \cdot 1$ to $2 \cdot 3$ ), as did their plasma cholesterol concentration $(6.6(0.9)$ v $6 \cdot 1(0 \cdot 7) \mathrm{mmol} / \mathrm{l}$; difference $=0.5(-0.3$ to 1.3$)$ and apolipoprotein $B$ concentration $(1.18(0.19) v 0.96(0.17) \mathrm{g} / \mathrm{l}$; difference $=0.2(-0.12$ to 0.52$)$. There was no significant change in haemoglobin $A_{1 c}$ concentration $(6.3(1.4) v 5.8$ $(2.4) \% ; \mathrm{p}=0.4)$ or body weight $(77(17) v 75(20) \mathrm{kg}$; $\mathrm{p}=0 \cdot 3)$. Among the controls no significant changes occurred in any of the variables measured.

The accuracy of patients' self monitoring was shown by the good reproducibility of measurements of control solutions (Precinorm, Boehringer Mannheim) and by the good correlation between the monthly triglyceride concentrations measured in the laboratory and the mean monthly preprandial values measured at home $(r=0.88, \mathrm{p}<0.001)$. There was a good correlation between individual triglyceride concentrations measured preprandially and at bedtime $(r=0 \cdot 84$, $\mathrm{p}<0.001)$. Three months after the end of the study triglyceride concentrations had risen in the patients who had monitored themselves from 1.6 to $2.2 \mathrm{mmol} / 1$ (NS), as had the patients' cholesterol concentrations (from $6 \cdot 1$ to $6.4 \mathrm{mmol} / \mathrm{l}(\mathrm{NS})$ ).

\section{Comment}

In this pilot study we showed that self monitoring of hypertriglyceridaemia in patients with non-insulin dependent diabetes mellitus improved lipid profiles over six months. Among patients using blood testing for glycaemic control this may be a useful adjunct to self management, giving feedback, encouraging adherence to a low fat diet, and possibly allowing lipid lowering treatment to be avoided. A larger study is required to establish whether improvement can be sustained.

We thank Boehringer Mannheim for financial support.

1 Barrett-Connor E, Orchard T. Diabetes and heart disease. In: Harris MI, Hammon RF, eds. National Diabetes Data Group. Diabetes in America. Bethesda, MD: US Department of Health and Human Services, 1984:1-41.

2 Fontbonne A, Eschwege E, Cambien F, Richard JL, Ducimetiere P, Thibult $\mathrm{N}$, et al. Hypertriglyceridaemia as a risk factor of coronary heart disease mortality in subjects with impaired glucose tolerance or diabetes. Results of the 11 year follow up of the Paris prospective study. Diabetologia 1989;32:300-4

3 Hanefield M, Schulze J, Fischer S, Julius U, Schmechel H, Haller H. The diabetes intervention study (dis). A cooperative multi intervention trial with newly manifested type 2 diabetes. Monogr Atheroscler 1985;13:98-103.

4 Howard BV. Lipoprotein metabolism in diabetes mellitus. I Lipid Res 1987;28:613-28.

5 Nutrition Subcommittee of the British Diabetic Association's Professional Advisory Committee. Dietary recommendations for people with diabetes: an update for the 1990s. Diabetic Med 1992;9:189-202.

(Accepted 16 December 1992)
Department of Pathological Biochemistry, Royal

Infirmary, Glasgow G4 OSF

J Johnston, principal

biochemist

D St J O'Reilly, consultant

clinical biochemist

Diabetes Centre, Royal

Infirmary, Glasgow G4 OSF

K R Paterson, consultant

physician

Correspondence to:

Ms Johnston.

BMF 1993;306:493-4

\section{Estimating urinary albumin excretion rate of diabetic patients in clinical practice}

J Johnston, K R Paterson, D St J O’Reilly

An increase in urinary albumin excretion is recognised as predicting impending renal failure in diabetic patients and cardiovascular disease in the general population. ${ }^{1}$ Measurement of the albumin excretion rate requires an accurately timed collection of urine, which is difficult in routine clinical practice. The albumin excretion rate correlates well with both the albumin concentration and the ratio of albumin to creatinine concentrations in first morning urine specimens. ${ }^{2}$ It has therefore been accepted that the urinary albumin concentration or albumin:creatinine ratio can be used to screen patients.

Before the clinical importance of such variables can be assessed the variability in a patient's urinary albumin concentration and albumin:creatinine ratio must be known. Data on individual variability have been published for small numbers of patients and controls, and coefficients of variation have been $31-43 \%$ under study conditions. ${ }^{34}$ This study was designed to establish intraindividual variability in urinary albumin concentrations and albumin:creatinine ratios under routine clinical conditions. 